\title{
Some Evolutionary Foundations for Price Level Rigidity
}

\author{
By Gilles Saint-Paul
}

\begin{abstract}
This paper shows that price rigidity evolves in an economy populated by imperfectly rational agents who experiment with alternative rules of thumb. In the model, firms must set their prices in face of aggregate demand shocks. Their payoff depends on the level of aggregate demand, as well as on their own price and their "neighbor's" price. The latter assumption captures local interactions. Despite the fact that the rational expectations equilibrium (REE) is characterized by a simple pricing rule that firms can easily adopt, the economy does not converge to the REE for all parameter values. When the volatility of monetary innovations is low and interactions among firms are high, the aggregate price level exhibits rigidity, in that it does not fully react to contemporaneous aggregate demand shocks. We discuss the role of the nature of experimentation, and of path dependence driven by interactions, in explaining these results. (JEL D83, D84, E3)
\end{abstract}

An important cornerstone of contemporary macroeconomic theory is the idea that the price level does not react one for one to nominal aggregate demand shocks. Otherwise, aggregate demand shocks would have a zero impact on real activity. It is therefore important to investigate the sources of such price rigidity. Historically, the literature has considered three options: assuming fixed and exogenous prices, imposing that prices can be changed only infrequently, and relying on some fixed "menu cost" of changing prices. 1 None of these options, however, is fully satisfactory.

In this paper, we investigate another route, namely, the extent to which sticky price-setting behavior may evolve as an equilibrium outcome in an economy populated by imperfectly ratio-

\footnotetext{
* Institut d'Economie Industrielle, Université des Sciences Sociales, 21 Allée de Brienne, Toulouse 31000, France (e-mail: gilles.saint-paul@univ-tlse1.fr). I am grateful to Niels Gottfries, three anonymous referees and participants at seminars at the Center for Economic Research and Graduate Education (Charles University, Prague), Uppsala University, and the Toulouse Macroeconomics Seminar for helpful comments and suggestions.

${ }^{1}$ See Robert J. Barro and Herschel I. Grossman (1971), Jean-Pascal Bénassy (1975, 1976), John B. Taylor (1980), Stanley Fischer (1977), Olivier J. Blanchard and Nobuhiro Kiyotaki (1987), Julio J. Rotemberg (1982), Andrew S. Caplin and Daniel F. Spulber (1987), Ricardo J. Caballero and Eduardo Engel (1993), N. Gregory Mankiw (1985), and George A. Akerlof and Janet L. Yellen (1985).
}

nal agents. We assume that such agents are not able to compute their optimal price-setting rule, and instead have to make experiments with rules of thumb. They drop rules that yield a low payoff in favor of those that yield a high payoff.

Firms are affected by the behavior of other firms because that behavior affects the aggregate price level. Another important ingredient of the model is local interaction, which is a simple local productive externality. It implies that an agent's payoff function depends on the price chosen by another, "contiguous" agent.

A crucial aspect of the model is that it is impossible to separate learning from action. Experiments have to be carried out on a full-scale basis, using the price charged by the firm to all its customers. By experimenting, firms exert externalities on other firms, because of local interactions and their impact on the aggregate price level. Consequently, experimentation by one agent affects the rules picked up by other agents.

We then ask the following questions: Does the economy converge to the REE? If not, do we observe any recognizable pattern in the behavior of aggregate prices? ${ }^{2}$

Despite that the REE price setting rule is

\footnotetext{
${ }^{2}$ The model can also potentially be used to derive predictions about the cross-sectional distribution of prices and its evolution through time, but this is a complex issue which we leave for further research.
} 
feasible, i.e., belongs to the set of rules that can be used by individual agents, it turns out that for a range of parameters the economy does not converge to that equilibrium. Rather, it converges to an equilibrium where the aggregate price level does not react one for one to contemporary money shocks, and is less volatile than money, contrary to what should happen in the REE. Furthermore, money is roughly neutral in the long run if the autocorrelation of money shocks is high, but not if it is low. To summarize, this economy exhibits the stylized macroeconomic properties of actual economies.

As we discuss below in greater detail, sticky price behavior arises from the combination of two factors: a low variance of monetary innovations, and a high degree of interaction among firms. If monetary innovations are very volatile, then the economy roughly converges to the REE. If interactions among firms are shut down, the economy also converges to the REE.

Experimentation by individual firms trying to find a better pricing rule plays a key role in generating these results. They sometimes change their behavior "at the margin" (local mutation), and sometimes experiment with an entirely new rule (global randomization). In such a case, the new rule will typically not exhibit money neutrality, reflecting the firms' lack of awareness of such a property when randomly picking a new rule. We show that even though global randomization occurs very infrequently, interactions among firms, along with a low volatility of monetary innovations, generate such strong path dependence that, even after a very long learning period, the price level does not fully react to nominal aggregate demand shocks.

While our variables are interpreted in terms of "money" and "prices," the model may provide evolutionary foundations for "rigid" behavior in a variety of settings. 3

The literature on evolution and adaptive

\footnotetext{
${ }^{3}$ In the working paper version of this paper, firms were simply minimizing a quadratic loss function, which depended on the difference between their choice variable and an aggregate shock, in addition to the difference between their choice variable and their neighbor's choice variable. The results were essentially the same, and clearly that can be applied to a large variety of settings.
}

learning is large, but has scarcely dealt with macroeconomic fluctuations. ${ }^{4}$ A recent exception is Albert Marcet and Juan Pablo Nicolini (2003), who are able to obtain recurrent hyperinflations in a Sargent-Wallace (1973) style model where they impose an adaptive learning model. To my knowledge, the present paper is the first to deal with price level stickiness. 5 Existing applications of adaptive learning to macroeconomics include Ramon Marimon et al. (1990), who deal with a problem of equilibrium selection based on Kiyotaki and Randall Wright (1989). Thomas J. Sargent (1993) presents various applications of bounded rationality to macroeconomics, including an interesting one on the paradox of trade, but none of them is about deriving price stickiness and monetary policy effectiveness from evolutionary principles. Jasmina Arifovic (1996, 2001), derives persistent fluctuations of the exchange rate in the context of a model where the rational expectations equilibrium is indeterminate. Applications to the time series properties of artificial stock markets have been studied by Blake LeBaron et al. (1999). Older applications to growth theory are found in Richard Nelson and Sidney Winter (1985), who develop a model of individual firms that learn about their optimal capital/labor ratio by trial and error.

A number of recent papers deal with price formation under near-rationality when people do not use all the available information (see Laurence Ball, 2000; Mankiw and Ricardo Reis, 2002). Michael Woodford (2002), extends the Robert E. Lucas, Jr. (1972) model of misperceptions by adding strong interactions among firms, as in the present paper, and noise in the subjective perceptions of current conditions. These papers consider very different deviations from rationality and learning processes than the present one; in particular, they do not

\footnotetext{
${ }^{4}$ A substantial fraction is devoted to convergence of Bayesian or least square learning to rational expectations. See Margaret Bray (1982), George W. Evans and Seppo Honhapohja (1995), Marcet and Sargent (1989), and JeanMichel Grandmont and Guy Laroque (1990).

${ }^{5}$ In Marcet and Nicolini (2003), the learning process is totally different from this paper's, since experimentation plays no role, nor do local interactions.
} 
consider experimentation with rules of thumb, which is this paper's key focus.

Related papers in microeconomics include Glenn Ellison (1993) and Ellison and Drew Fudenberg (1993), who study the role of local interaction in determining outcomes in evolutionary games; and Joseph E. Harrington (1998, 1999), who shows, in particular, how rigid agents may be more successful in evolutionary hierarchical contests. None of this work is concerned with macroeconomic fluctuations.

Interactions and externalities in the context of the traditional sticky price literature (based on menu costs or exogenously imposed timing restrictions on price setting) have been studied by Ball and David Romer (1991), and Assar Lindbeck and Dennis J. Snower (1999). ${ }^{6}$ The former, in particular, find that money is more likely to have significant effects on prices, the greater the degree of real rigidity (as defined by a flat marginal cost curve) in price setting, and the greater the strategic complementarities between producers' price-setting behavior. This paper's results are similar in that aggregate price inertia arises in the zone where local interactions are strong.

The paper is organized as follows. In Section I, we set up the model and derive the rational expectations equilibrium. In Section II, we describe how pricing rules are set and how they evolve by selection. Main numerical results are reported in Section III, while Section IV discusses some intuition for these results. Section $\mathrm{V}$ performs comparative statics and robustness checks.

\section{A Model}

The model uses the standard toolboxes of modern macroeconomic theory. ${ }^{[]}$There are overlapping generations of agents who live for two periods. In the first period of their life they are endowed with a fixed quantity of labor which they supply to the market, and in the second period they consume. Fiat money issued

\footnotetext{
${ }^{6}$ A more general analysis of the aggregate consequences of local interactions has been developed by Steven $\mathrm{N}$. Durlauf (1991, 1996), and William Brock and Durlauf (2001).

${ }^{7}$ See, for example, Romer (2001) and Woodford (2003).
}

by the government is the only store of value between the two periods. We assume that profits are rebated to the young, as is seigniorage.

There are $N$ differentiated goods, each produced by a monopoly. Utility is a composite CES index of consumption of each good:

$$
U\left(c_{1}, \cdots c_{N}\right)=\sum_{i=1}^{N} c_{i}^{\alpha} .
$$

Denoting by $P_{i t}$ the price of good $i$ at date $t$, the demand for good $i$ by an old worker with $M_{0 t}$ units of money at the beginning of period $t$ is thus

$$
\frac{M_{0 t}}{P_{t}}\left(\frac{P_{i t}}{P_{t}}\right)^{-\eta}
$$

where $\eta=1 /(1-\alpha)$ and

$$
P_{t}=\left(\sum_{i=1}^{n} P_{i t}^{1-\eta}\right)^{1 / 1-\eta}
$$

is the usual aggregate price index. Aggregating, we get the standard final demand function for good $i$ :

$$
x_{i}\left(M_{t}, P_{i t}, P_{t}\right)=\frac{M_{t}}{P_{t}}\left(\frac{P_{i t}}{P_{t}}\right)^{-\eta}
$$

where $M_{t}$ is the total money stock held by the old at date $t .8$

An important ingredient in the model is the existence of local interactions between firms. To keep things simple we assume that each firm $i$ exerts a positive productive externality on its "right neighbor," defined as firm $i+1$ if $i<n$, and as firm 1 if $i=n$. That is, to produce $y_{i}$ units of good $i$, it needs $a y_{i}^{\beta} / y_{i-1}^{\beta(1-\gamma)}$ units of labor.

\footnotetext{
${ }^{8}$ In this model, total nominal aggregate demand is given only by $M_{t}$. The budget constraint of the young implies

$$
w_{t} L_{t}+\Pi_{t}+S_{t}=M_{t+1}
$$
}

where $S_{t}$ is seignoriage and $\Pi_{t}$ is profits. As $S_{t}=M_{t+1}-$ $M_{t}$, that is equivalent to the income/expenditure identity

$$
Y_{t}=w_{t} L_{t}+\Pi_{t}=M_{t} .
$$


Thus, an increase in firm $i$ 's left-neighbor output, $y_{i-1}$, increases firm $i$ 's productivity. The parameter $\gamma$ captures the intensity of local interactions. The smaller is $\gamma$, the greater the effect of a firm's left neighbor on its productivity. Another form of interaction could be considered, such as firms buying intermediate inputs from each other, but it would lead to a more complex formulation. 9

Thus, denoting by $w_{t}$ the wage at date $t$, the cost function for good $i$ is

$$
c\left(y_{i t}, w_{t}\right)=a y_{i t}^{\beta} w_{t} / y_{i-1}^{\beta(1-\gamma)} .
$$

The model is closed by specifying the labor market. For simplicity, we assume real wages are rigid, so that the nominal wage at $t$ satisfies $w_{t}=\omega P_{t}$; we also assume that the young's labor endowment is large enough so that the economy will always be in an underemployment equilibrium, which prevents us from having to distinguish between different regimes. Such rigidity can be interpreted as the outcome of minimum wages, union wage setting, or efficiency wages. 10

\footnotetext{
${ }^{9}$ Such a model has actually been tried. While the numerical results are similar, that approach is plagued by multimodality in a firm's profit function, which sometimes drives equilibrium prices toward their numerical upper bound and makes it difficult to interpret the results. For this reason, we stick with a simple local externality.

${ }^{10}$ A fairly similar, but more complicated, model would be obtained by assuming that the young do not work but simply own claims to profits, and that there exists an additional class of workers who live only one period, during which they work and consume, and have a linear utility function, with a constant marginal disutility of labor and a constant marginal utility of consumption. They supply labor with an infinite elasticity at real wage $\omega$, which pins it down in the same way as in the model. The complication is that one would then have to add the demand for goods coming from these workers to compute the equilibrium level of output and employment. On the other hand, assuming that the young themselves are on their Walrasian labor supply curve brings two complications. First, given that they consume only in the following period, they face a nontrivial optimization problem, since next period's expected price level affects their labor supply today. In the context of evolutionary learning, one then has either to assume that contrary to price-setters, they are fully rational, which is somewhat inconsistent, or to specify a learning process for optimal labor supply. It would then be difficult to disentangle its effects from those of adaptive learning by pricesetters, which is the main focus of this paper. Second, it
}

Firms maximize their current profits, given by

$$
\pi_{i t}=P_{i t} y_{i t}-c\left(y_{i t}, w_{t}\right) .
$$

For simplicity, we assume they neglect the effect of their own price-setting decisions on the aggregate price level. ${ }^{[1]}$ At the beginning of each period, all firms set their price $P_{i t}$ simultaneously, knowing the current money stock. The first-order condition characterizing an equilibrium is

$$
\left(P_{i t}-\frac{\partial c\left(y_{i t}, w_{t}, P_{i-1, t}\right)}{\partial y_{i t}}\right) \frac{\partial y_{i t}}{\partial P_{i t}}+y_{i}=0
$$

or equivalently

$$
P_{i t}=P_{t} \frac{\eta}{\eta-1} a \beta \omega \frac{y_{i t}^{\beta-1}}{y_{i-1, t}^{\beta(1-\gamma)}} .
$$

The following proposition characterizes a rational expectations equilibrium, which will be used as our benchmark.

PROPOSITION 1: There exists a symmetrical rational expectations equilibrium such that

(i) Each firm sets the same price $P_{i t}=P_{0 t}$

(ii) Each firm's output level is given by

$$
y_{i t}=\left(\frac{\eta-1}{\eta a \omega \beta N^{1 / 1-\eta}}\right)^{1 / \beta \gamma-1}=y^{*}
$$

(iii) Total employment is given by

$$
L_{t}=N a y^{* \beta \gamma}
$$

would introduce a genuine channel of nonneutrality of monetary shocks, even in the fully rational case, since a temporary money shock increases expected inflation, thus reducing the value of holding money, which in turn affects labor supply. Our assumption of a rigid real wage in terms of the current price level dispenses us from having to deal with optimization by the young, and allows for a simple benchmark rational expectations equilibrium such that nominal prices are directly proportional to the money stock regardless of the time series properties of the money supply shock.

${ }^{11}$ That makes the equilibrium much easier to compute but does not affect the property that money is neutral. 
(iv) The common price level is given by

$$
P_{0 t}=\frac{M_{t}}{N y^{*}} .
$$

Furthermore, if

$$
\gamma>\frac{\eta-1}{\eta}
$$

then this is the only equilibrium.

\section{PROOF:}

\section{See Appendix.}

The equilibrium has the traditional dichotomy properties of models with flexible prices. A monetary shock has no real effect and only increases all prices proportionally. In the absence of other sources of shocks, output and employment are constant and equal to their natural level, which is affected by real rigidities $\omega$ but not by money. Uniqueness is important, because when we consider bounded rationality, we want to abstract from equilibrium selection issues. Whenever the REE equilibrium is unique, one is confident that any simulation that does not converge to the equilibrium one has computed is associated with a genuine deviation from the REE rather than with selection of another equilibrium.

\section{Description of the Procedure}

We study what happens when the economy is populated not by profit maximizers but by boundedly rational firms which gradually learn their payoff. These firms are experimenting with alternative price rules and select the best rules, i.e., those that yield the highest payoff.

\section{A. The Money Creation Process}

To minimize numerical problems, I assume that the log of the money supply process, $m_{t}=$ $\ln M_{t}$, follows a stochastic process which confines to the $[0,1]$ interval. I also constrain the prices chosen to lie within that interval. Parameters will be chosen so that this feature does not rule out the rational expectations equilibrium.
More specifically, I will impose that $N y^{*}=1$, so that the REE pricing rule is just $P_{i t}=M_{t}$.

The money process to which this economy is subjected is an AR1:

$$
m_{t+1}=\rho m_{t}+\varepsilon_{t}
$$

where $\varepsilon$ is distributed uniformly over $(\bar{m}(1-$ $\rho)-\sigma, \bar{m}(1-\rho)+\sigma)$, with $0.5<\bar{m}<1$, and $\sigma \leq(1-\rho)(1-\bar{m}) . \sigma$ thus parameterizes the variance of innovations to the money stock and is constrained so that the resulting values of $m_{t}$ remain between 0 and 1 .

\section{B. Specifying Rules of Thumb}

The learning procedure is specified as follows. At each date $t$, firm i's information set is given by $S_{i t}=\left\{p_{i t-1}, p_{i-1, t-1}, m_{t-1}, m_{t}\right\}$, where $p_{i t}=\ln P_{i t}$. That is, they use information on current and lagged monetary shocks as well as their left neighbor's and own lagged price level. For simplicity, we rule out the use of variables with a greater lag, as well as prices set by firms other than their left neighbor, i.e., the one that exerts an externality on them.

Firms then behave according to a rule that specifies their log current price $p_{i t}$ as a function of that information set. This rule is specified as follows: 12

$$
\begin{aligned}
\hat{p}_{i t}= & c_{0, i t}+c_{1, i t} \hat{m}_{t-1}+c_{2, i t} \hat{m}_{t}+c_{3, i t} \hat{p}_{i t-1} \\
& +c_{4, i t} \hat{p}_{i-1, t-1}
\end{aligned}
$$

The pricing rule followed by firm $i$ at date $t$ is represented by the vector of parameters $\left(c_{0}, c_{1}\right.$, $\left.c_{2}, c_{3}, c_{4}\right)$. The hat "^" denotes the logistic transformation:

\footnotetext{
${ }^{12}$ Note that the problem is specified in "analog," rather than digital terms, as in Nelson and Winter (1985), but contrary to the more recent literature which uses genetic algorithms, classifiers, or neural networks. See the Santa Fe Institute volumes (Philip N. Anderson et al., 1988; W. Brian Arthur et al., 1997) for discussions. A previous attempt to formulate the problem in terms of classifier-style rules was unsuccessful, essentially because mutation or generalization of crucial bits yielded rules that made little sense.
} 


$$
\hat{x}=\ln \frac{x}{1-x} .
$$

The use of this transformation guarantees that regardless of the values of $\left\{p_{i t-1}, p_{i-1, t-1}\right.$, $\left.m_{t-1}, m_{t}\right\}$ and of the rule parameters $\left(c_{0}, c_{1}, c_{2}\right.$, $c_{3}$ ), the log price quoted by each firm remains in the $(0,1)$ interval.

Two things should be noted regarding the price-setting behavior defined by equation (3). First, price setters do not conceptualize the notions of equilibrium, expectations, or parameters. Their mental ability does not go beyond mechanically applying rules such as (3) and they learn through experience which rules are better. Hence, rational expectations, or even expectations, are meaningless concepts for these agents. Similarly, Bayesian learning would be impossible, since a Bayesian must formulate a probability model with an underlying parameter to be learned. These concepts are out of reach for our agents. Second, the REE is a special case where all firms follow the rule given by $c_{2}=1$, $c_{1}=c_{3}=c_{0}=c_{4}=0$. Therefore, it is perfectly attainable. Failure to converge to the REE, if it occurs, cannot come from the agents' inability to adopt the correct behavior.

The rule coefficients can have any value. To prevent the economy from having unstable dynamics, however, we will consider only those rules that satisfy the following restriction:

$$
\left|c_{3}\right|+\left|c_{4}\right|<1
$$

\section{Experimentation and the Evolution of Rules}

The economy starts from an arbitrary distribution of prices. At the beginning of time, firms select a rule randomly and apply it to set their price. That rule is selected by picking each coefficient $c_{i}$ in the interval $[-1,1]$ using a uniform distribution.

After a rule has been used for at least $T$ periods, firms may decide to experiment with another rule. There are two modes of experimentation, denoted by $e=1,2$. At each date $t$ there is a probability $q_{\text {iet }}$ that firm $i$ abandons its rule and experiments with another one under mode $e$ instead. The initial value of $q_{\text {iet }}$ is ex- ogenously set equal to $q_{\max }$, which is also its maximum value. The two modes are:

(a) Local mutation $(e=1)$. In such a case the new rule is defined by

$$
c_{i t+1}=c_{i t}+\mu z_{i t}
$$

where $\mu$ is a parameter capturing the size of a local mutation, and $z_{i t}$ is an i.i.d. random variable distributed over $(-1,1)$.

(b) Global randomization $(e=2)$. In such a case the new rule is drawn randomly in the same way as the initial one.

In both cases, if the new rule does not satisfy restriction (4), a new rule is drawn until (4) is satisfied.

During the experiment the new rule is used but the firm remembers the preceding rule as well as the average payoff experienced with it so far. Experimentation lasts for at least $T$ periods, after which the average payoff per period is compared with that of the previous rule (therefore, there is no discounting). If it is inferior, then the firm returns to the previous rule, and the probability of experimenting according to mode $e$ is adjusted downward according to the following formula:

$$
q_{i e t+1}=(1-\theta) q_{i e t}+\theta q_{\min } .
$$

If it is better, then the experiment continues as long as the average payoff is higher than that of the previous rule, up to the point where the total duration of the experiment equals $\bar{T}$, where $\bar{T}=\min \left(100, T^{\prime} / 2\right)$, and $T^{\prime}$ is the total length of time during which the previous rule has been used. At this point, the new rule is definitely adopted, and the probability of experimenting according to mode $m$ is adjusted upward using the following formula:

$$
q_{i e t+1}=(1-\theta) q_{i e t}+\theta q_{\max } .
$$

If the average payoff of the experimented rule falls below that of the previous rule at any point between $T$ and $\bar{T}$, then the experiment is immediately abandoned and one reverts to the previous rule.

This rather complex procedure is used to prevent a rule that has proven quite good for a 
Table 1 -Parameters of the Benchmark Simulation

\begin{tabular}{llc}
\hline \hline Parameter & \multicolumn{1}{c}{ Meaning } & \multicolumn{1}{c}{ Value } \\
\hline$T$ & Minimum length of experimentation & 15 \\
$q_{\max }$ & Maximum probability of experimentation & 0.03 \\
$q_{\min }$ & Minimum probability of experimentation & 0.001 \\
$\theta$ & Adjustment speed of experimentation probabilities & 0.1 \\
$\mu$ & Size of a local mutation & 0.05 \\
$\bar{m}$ & Mean of log money stock & 0.6 \\
$\rho$ & Autocorrelation of money shocks & 0 \\
$\beta$ & Curvature of marginal cost curve & 3 \\
$\eta$ & Elasticity of substitution between goods & 5 \\
$a$ & Productivity & 1 \\
$\omega$ & Real wage & $\frac{\eta-1}{\beta a \eta} n^{\beta \gamma-1+1 /(\eta-1)}$ \\
\hline
\end{tabular}

very long time to be abandoned in favor of a rule that has improved on it for a much shorter time, say because of an unlikely sequence of shocks. Thus we impose a probation period set to half the duration of the previous rule before an experiment is adopted. But, given that firms will eventually find good rules that will be used for a very long time, in order to avoid experiments that are too long we put a cap of 100 periods on this probation period.

\section{Results}

We now describe how the model was solved numerically and report our main quantitative results. Table 1 summarizes the values chosen for the parameters. The total number of firms is heavily constrained by computation time and was set to 10 . The minimum length of time a rule must be used before another can be tried is set to $T=15$. Experimentation probabilities vary between $q_{\min }=0.001$ and $q_{\max }=0.03$. We have set $\mu=0.05$, and $\theta=0.1$. The mean $\bar{m}$ was chosen to be equal to 0.6 . The benchmark value for autocorrelation of the money shocks $\rho$ is set to zero, which allows for the wider possible range of variation for the dispersion of monetary innovations. $\beta$ was set equal to 3 .

We are interested in how the average behavior of the economy depends on $\gamma$ and $\sigma$. Therefore, we tried 10 values of $\sigma, \sigma=i(1-\bar{m}) / 10$, for $i=1, \ldots, 10 ; \frac{13}{13}$ and 4 values of $\gamma, \gamma=1,0.9$,

\footnotetext{
${ }^{13}$ The maximum value of $i$ is $10(1-\rho)$.
}

0.8 , and 0.7. We pick $\eta=5$, implying that the condition $\gamma>(\eta-1) / \eta$ is satisfied for three values of $\gamma$ but not for $\gamma=0.7$. Uniqueness is therefore not granted for that value. Finally, productivity is normalized to one, and the real wage parameter $\omega$ is determined residually to enforce the $N y^{*}=1$ constraint.

Initial prices were drawn from a uniform distribution over $(0,1)$. Initial values of $c_{i}, i=$ $0, \ldots, 3$, were drawn using a uniform distribution over $[-1,1]$, as already stated. I then let the economy evolve for 500,000 periods, and then for another 3,000 periods, during which I collect statistics on the aggregate price level and the aggregate money stock. This was repeated 10 times for each pair $(i, \gamma)$, thus generating 10 simulations for each set of parameters. For each of these simulations I characterize the behavior of the economy by running the following regression over the final 3,000 periods during which statistics were collected:

(5) $\bar{p}_{t+1}=a_{0}+a_{1} m_{t+1}+a_{2} m_{t}+b_{2} \bar{p}_{t}+\eta_{t}$

where $\bar{p}_{t}$ is the aggregate price level defined as the average across firms of individual prices:

$$
\bar{p}_{t}=\frac{1}{n} \sum_{i=1}^{n} p_{i t} .
$$

Note that this regression is not meant to recover the rules followed by individual firms, but the time series properties of the aggregate price level, summarized by coefficients $a_{0}, a_{1}, a_{2}$, and $b_{2}$. 


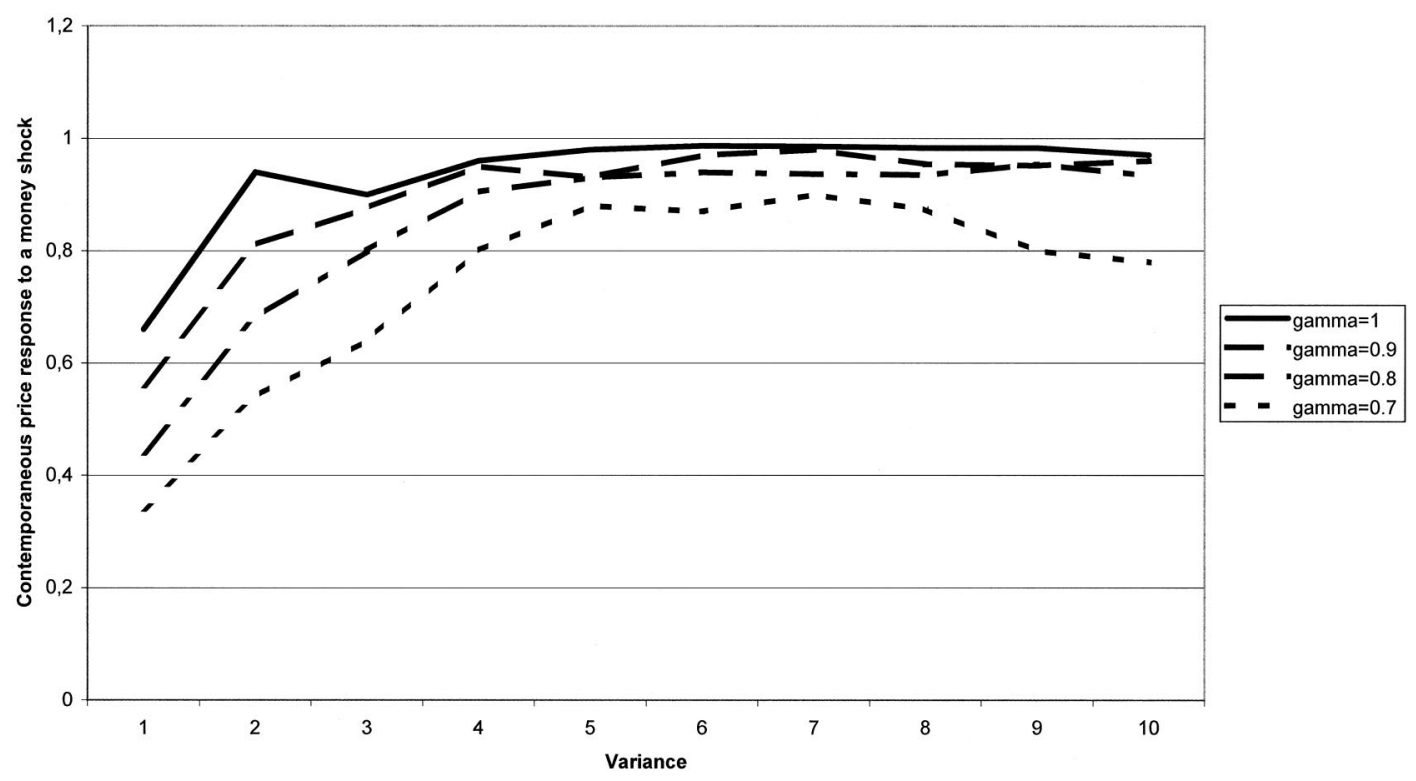

FIGURE 1

Under the REE, one should have $a_{2}=$ $b_{2}=0, a_{1}=1$, and the regression should yield an $\mathrm{R}^{2}$ equal to 1 . Even if individual firms end up adopting such a rule, one should expect small deviations from this ideal point because a fraction of firms are experimenting. In the long run, this fraction should not exceed $q_{\text {min }}$, as experimentation should yield lower payoffs than the optimal rule.

If $0 \leq a_{1}<1$ then prices are "rigid" in the sense that they react less than one for one to monetary shocks.

If $a_{1}+a_{2}+b_{2} \approx 1$, then money is "neutral" in the long run, in that prices would eventually adjust fully to a permanent change in $m$. Note, however, that such a change is a zero-probability event. As long as $p$ is stationary, it tends to return to its mean, as does $m$, so that any rejection of the long-run neutrality hypothesis should be interpreted with caution. Things would be different if the driving process for $m$ were I(1). If $a_{1}+a_{2}+b_{2}<1$, then the long-run effect of a permanent money shock on prices is $\left(a_{1}+a_{2}\right) /\left(1-b_{2}\right)$. The difference between the long-run and the short-run effects is equal to $a_{2}+a_{1} b_{2} /\left(1-b_{2}\right)$ and is a measure of price inertia. 14

The key parameter of interest is $a_{1}$, the response to the contemporaneous money innovation. The results are summarized in Figure 1, where the variance of $\varepsilon$ is indexed by $i$, the fraction of the maximum possible dispersion of $\varepsilon$. For each parameter set, the reported numbers are the average across 10 simulations of the estimated value of $a_{1}$. At low levels of the variance of innovations, there is substantial price rigidity; when the variance becomes larger, the coefficient is close to the predicted REE value of 1. Furthermore, prices are stickier the greater the degree of interactions among firms; while for $\gamma=1$, one is close to the REE at $i=2\left(a_{1}=0.94\right)$ or above, for $\gamma=0.7, a_{1}$ is below 0.9 , and exceeds 0.8 only for $i \geq 4$. For $\gamma=0.7$, however, there is an eventual, anom-

${ }^{14}$ Alternative measures would be the mean lag implicit in (5), $M L=a_{2}+a_{1} b_{2} /\left[\left(1-b_{2}\right)\left(a_{2}+a_{1}\right)\right]$, or $a_{2}+a_{1} b_{2}$, which tells us the effect of a purely transitory money shock on prices one period ahead. The formulas are pretty similar. 
TABLE 2-SHORT-RUN VERSUS LONG-RUN EFFECTS FOR Selected Values of $i$

\begin{tabular}{lcc}
\hline \hline Parameters & $\begin{array}{c}\text { Short-run } \\
\text { effect }\end{array}$ & $\begin{array}{c}\text { Long-run } \\
\text { effect }\end{array}$ \\
\hline$i=1, \gamma=1$ & 0.66 & 0.51 \\
$i=1, \gamma=0.9$ & 0.56 & 0.83 \\
$i=1, \gamma=0.8$ & 0.44 & 0.52 \\
$i=1, \gamma=0.7$ & 0.34 & 0.48 \\
$i=2, \gamma=1$ & 0.94 & 0.86 \\
$i=2, \gamma=0.9$ & 0.81 & 0.74 \\
$i=2, \gamma=0.8$ & 0.68 & 0.65 \\
$i=2, \gamma=0.7$ & 0.54 & 0.71 \\
\hline
\end{tabular}

TABle 3-STANDARd Deviation of $a_{1}$

\begin{tabular}{lcccc}
\hline \hline$i \gamma$ & 1 & 0.9 & 0.8 & 0.7 \\
\hline 1 & 0.15 & 0.13 & 0.14 & 0.2 \\
4 & 0.06 & 0.04 & 0.07 & 0.15 \\
9 & 0.03 & 0.05 & 0.06 & 0.18 \\
\hline
\end{tabular}

alous decline in $a_{1}$ as $\sigma$ becomes large. ${ }^{15}$ That is not observed for other values of $\gamma$.

Table 2 reports the "long-run" effects of a monetary innovation, for the two lowest values of $i$. We see that the long-run effect is not necessarily greater than the short-run effect, and often quite below one. Thus, there is no sign of long-run neutrality, nor of inertia. As already stated, nonneutrality in the long run should be taken with caution, given that actual monetary shocks are very transitory in these simulations. Simulations with a high value of $\rho$, reported in Section V, suggest a long-run effect substantially above the short-run effect (hence large inertia), and close to one (hence near long-run neutrality).

Another feature is the wide dispersion in the estimated parameters, especially for parameter values where there is price stickiness (i.e., a low variance of $\varepsilon$ or a strong degree of interactions). This is documented in Table 3, and suggests that the time series behavior of prices after 500,000 periods is quite path-dependent.

Another approach to measuring price stickiness is to compute the ratio between the standard deviation of the price level and that of the

\footnotetext{
15 That phenomenon may have to do with the fact that the uniqueness condition is violated for $\gamma=0.7$.
}

Table 4-Relative Standard Deviation of the Aggregate Price Level

\begin{tabular}{lcccc}
\hline \hline$i \backslash \gamma$ & 1 & 0.9 & 0.8 & 0.7 \\
\hline 1 & 0.77 & 0.7 & 0.65 & 0.62 \\
4 & 0.97 & 0.96 & 0.92 & 0.81 \\
9 & 0.99 & 0.95 & 0.96 & 0.81 \\
\hline
\end{tabular}

money stock. This ratio is reported in Table 4 , which confirms the results of Figure 1, that prices are stickier the greater the degree of interactions and the smaller the variance of money shocks.

\section{Elements of Explanation}

In this section we provide some intuition about the results of the preceding section. Inevitably, there is a heuristic dimension to the intuition I am about to provide, as is always the case with numerical results. The key feature driving the results is the link between experimentation and interactions between firms.

In the model, firms interact via two channels: first, their costs are affected by their neighbor's output whenever $\gamma<1$. Second, they exert pecuniary externalities because a firm's pricing decisions affect the aggregate price level, which matters to other firms. That latter effect is present even when $\gamma=1$. Because of these interactions, firms face two sources of shocks: monetary shocks and experimentation by other firms. They must find a rule that does well in the face of the two types of shocks. This logic drives them away from finding the REE, and instead they tend to converge to rules that exhibit price stickiness.

\section{A. The Role of Global Randomization}

Global randomization plays an important role. Firms periodically experiment with randomly selected rules that on average do not react to current monetary conditions, since all coefficients are drawn from a distribution with zero mean. That is, the way they experiment globally does not reflect any prior about the effect that monetary shocks should have on average. Global experimentation does not work well eventually, although it is important 
Table 5-Sensitivity to the Initial Rule When Global Randomization Is Not Allowed

\begin{tabular}{llc}
\hline \hline & $\begin{array}{c}\text { Initial rule: } \\
\text { REE }\end{array}$ & $\begin{array}{c}\text { Initial rule: } \\
\text { Fixed price }\end{array}$ \\
\hline$i=1, \gamma=1$ & 0.996 & 0.257 \\
$i=1, \gamma=0.8$ & 0.986 & 0.239 \\
$i=1$, no interactions & 0.999 & 0.998 \\
$i=10, \gamma=1$ & 1.0 & 0.6 \\
$i=10, \gamma=0.8$ & 0.995 & 0.81 \\
$i=10$, no interactions & 1.0 & 0.999 \\
\hline
\end{tabular}

for avoiding being locked at an inefficient local optimum. In most of our simulations, the rate of global experimentation has fallen very close to its minimum value of $q_{\min }$ after 500,000 periods. Nevertheless, the way global experimentation is conducted has an important impact on the long-run behavior of the economy. To illustrate this, we ran experiments where the distribution of $c_{2}$ in global experimentation has a mean of one instead of zero. That is, global randomization on average yields rules with money neutrality. These experiments roughly converge to economies where money is neutral. How can global experimentation have such an impact even though it plays such a small role in the long run? The explanation is that local mutation alone generates considerable path dependence, i.e., very little selective pressure. 16 Therefore, even though global randomization occurs very infrequently, because of strong path dependence, its characteristics have a large impact on the time series behavior of the aggregate price level.

\section{B. Path Dependence}

Table 5 illustrates path dependence by reporting the average coefficient on money across 10 simulations when the global experimentation mode has been shut down (i.e., $q_{i 2 t}=0, \forall t$ ). It compares two initial conditions: one where

\footnotetext{
16 There are some grounds to believe that under pure local mutation, the economy would eventually converge to the REE, as the estimated coefficient $a_{1}$ gets closer to one if one waits much longer. But I could not establish such convergence even after waiting a very long time.
}

firms start from the rational expectations rule, $c_{2}=1, c_{i}=0, i \neq 2$; the other where they start from a fixed price rule, $c_{i}=0, \forall i$. The estimated coefficient on money $c_{m}$ is reported for various values of $\gamma$ and $\sigma$, as well as for a model where $\gamma=1$ and $p$ was replaced by $m$ in the firm's welfare function, which shuts down all interactions between firms, including the pecuniary externality exerted through the aggregate price level.

The following interesting pattern emerges. First, when the initial rule is the REE, the economy remains at the REE equilibrium. 17 Second, when all interactions are shut, firms converge to the REE regardless of initial conditions: there is no path dependence absent interactions. Third, interactions among firms generate a large degree of path dependence. Fourth, path dependence is stronger the smaller the variance of monetary innovations, i.e., the lower $i$. Fifth, and somewhat surprisingly given the results of Figure 1, local interactions do not seem to reinforce path dependence as compared to the simple pecuniary externality, at least for the particular experiment of Table 5. Sixth, allowing global randomization brings the economy significantly closer to the REE than having just local mutations-that is, it is a "useful tool," even though its nature generates stickiness in the long run.

Given that these sets of simulations differ only by their initial conditions, price stickiness in the long run must be the "echo" effect of the initial, fixed-price rule.

To summarize, when path-dependence is high, infrequent periods of global randomization have a lot of influence on the economy's long-run behavior. Given that global randomization on average does not generate rules that react one for one with the money stock, that is eventually reflected in price stickiness.

The remaining part of the puzzle is: why is path-dependence so heavily affected by interactions among firms and the variance of innovations?

\footnotetext{
${ }^{17}$ That is not the case when global randomization is allowed (see Section V).
} 


\section{The Role of Interactions}

The way interactions, especially local interactions, between agents magnify path dependence has been seen in a number of contexts (see Durlauf, 1991, 1996). Here, both the pecuniary externality and local interactions imply that firms, to some extent, want their prices to track those charged by other firms. Rules that are not good at such tracking will tend to be rejected, more so the stronger the interactions. Once one uses a rule that does fairly well at tracking other firms' prices, experiments will tend to be rejected, even if the new rule were to perform better provided other firms could simultaneously change their rule. Thus, one is more likely to revert to the initial rule, which generates more persistence in pricing behavior. In other words, it is the lack of coordination among firms in setting the timing of experimentation that generates high persistence under strong interactions.

In addition, strong interactions also magnify the nonneutrality of global randomization. As global experimentation by neighbors yields rules that are not typically reactive to money, the firm will tend to reduce its own price sensitivity to money in order to respond to such periods. By doing so, it also increases the incentives by other firms to be sticky, as they are affected by its own pricing rules. Thus, rigidity spreads across firms, more so the stronger the interactions.

\section{The Role of Monetary Volatility}

As in the famous Lucas (1972) misperception, firms face a signal extraction problem, although of a different type. They are subject to monetary shocks and shocks coming from experimentation by other firms. Rules that are closer to the REE will perform better the larger the variance of monetary innovation, because monetary shocks then represent a greater proportion of the shocks faced by the firm. This is indeed what is observed in the previous sections' simulations. Monetary volatility also acts through another channel by increasing path dependence: as Table 5 shows, path dependence is lower when volatility is higher. Intuitively, the lower the variance of money shocks, the smaller the penalty for pursuing rules that react inadequately to money shocks but are good are tracking other firms' price behavior. So, if one starts with initial rules that are fairly good for such tracking (as is the case if everybody initially follows the same, non-REE, rule), one is more likely to stay close to these rules if the variance of monetary shocks is smaller.

The preceding discussion implies that it is crucial, for our results to hold, that learning by experimentation cannot be insulated from actual price-setting behavior. If one could experiment on a microscopic scale, then such experimentation would not exert externalities upon others, and there would not be inertia in the pricesetting rules.

\section{Robustness Checks and Comparative Statics}

I now report some robustness checks and comparative statics exercise, and provide some intuition whenever a parameter change seems to affect the results significantly.

\section{A. Robustness}

Table 6 reports the effects on the main coefficient of interest, $a_{1}$, of changing a number of parameters. For parsimony and to save on computing time, I have performed these exercises for only four pairs $(i, \gamma)$. The "benchmark" results correspond to the simulations reported in Section III.

The following conclusions emerge:

(a) The key results of near-neutrality when the variance of innovations is high, and that stronger interactions increase price rigidity, are robust to all the parameter changes we have performed.

(b) Changing the size of mutations $\mu$ (3), the waiting time before collecting statistics (4), the number of firms $n$ (5), the width of the interval where coefficients are drawn when there is global randomization (8), or the demand elasticity $\eta$ (11) do not seem to have a significant, systematic impact on the degree of rigidity.

(c) A doubling of the rate of experimentation (7), or a doubling of the minimum duration of experiments (6), tends to reduce $a_{1}$, i.e., 
TABLe 6-Robustness CHECKS

\begin{tabular}{|c|c|c|c|c|}
\hline Experiment & $\begin{array}{c}\gamma=1, i=1 \\
a_{1}\end{array}$ & $\begin{array}{c}\gamma=0.8, i=1 \\
a_{1}\end{array}$ & $\begin{array}{c}\gamma=1, i=10 \\
a_{1}\end{array}$ & $\begin{array}{c}\gamma=0.8, i=10 \\
a_{1}\end{array}$ \\
\hline 1. Benchmark & 0.66 & 0.49 & 0.99 & 0.93 \\
\hline 2. Starting from REE rule & 0.8 & 0.59 & 0.98 & 0.91 \\
\hline 3. $\mu=0.1$ & 0.75 & 0.4 & 0.96 & 0.9 \\
\hline 4. Waiting $10^{6}$ periods & 0.78 & 0.41 & 0.97 & 0.95 \\
\hline 5. $n=20$ & 0.69 & 0.42 & 0.96 & 0.91 \\
\hline 6. $T=30$ & 0.56 & 0.36 & 0.96 & 0.87 \\
\hline 7. Doubling $q_{\min }, q_{\max }$ & 0.63 & 0.39 & 0.95 & 0.91 \\
\hline 8. $c_{i} \in[-2,2]$ & 0.57 & 0.54 & 0.96 & 0.68 \\
\hline 9. $\rho=0.9$ & 0.73 & 0.55 & - & - \\
\hline 10. $\rho=0.9$ (LR effect) & 0.97 & 0.81 & - & - \\
\hline 11. $\eta=3$ & 0.63 & 0.43 & 0.97 & 0.97 \\
\hline 12. $\beta=4.5$ & 0.61 & 0.42 & 0.9 & 0.86 \\
\hline
\end{tabular}

Table 7-Dispersion of Coefficients $a_{1}$ across Simulations with Different Waiting Times

\begin{tabular}{|c|c|c|c|c|c|c|c|c|}
\hline \multirow{2}{*}{$\frac{\text { Experiment }}{\text { Waiting time }\left(\times 10^{5}\right)}$} & \multicolumn{2}{|c|}{$\gamma=1, i=1$} & \multicolumn{2}{|c|}{$\gamma=0.8, i=1$} & \multicolumn{2}{|c|}{$\gamma=1, i=10$} & \multicolumn{2}{|c|}{$\gamma=0.8, i=10$} \\
\hline & 5 & 10 & 5 & 10 & 5 & 10 & 5 & 10 \\
\hline Standard deviation & 0.15 & 0.136 & 0.14 & 0.137 & 0.03 & 0.035 & 0.068 & 0.06 \\
\hline
\end{tabular}

increase the level of rigidity. That is consistent with the interpretations provided in the preceding section: when experimentation by other firms is a more important source of shocks, tracking others' prices gets more weight relative to tracking the money stock, and prices are more rigid.

(d) An increase in the curvature of the cost function (12) increases price rigidity moderately, but systematically. That result is paradoxical, as more variable marginal costs make price rigidity more costly. It may be due to the fact that $\beta$ also enters, along with $\gamma$, in the definition of the local productive externality.

(e) An increase in the persistence of shocks (9) tends to increase the contemporaneous response of prices. That is understandable, since responding adequately to a money shock is more valuable if it is more persistent. Furthermore, if money shocks are persistent, there is price inertia: the long-run effect of a money shock is substantially larger than its short-run effect (10), and one is not far from long-run neutrality. In contrast, with $\rho=0$, there is no systematic difference between long-run and short-run effects. Price setters now correctly implement long-run neutrality when monetary shocks have long-lasting effects.

\section{B. Convergence}

Comparing simulation results when one waits one million rather than 500,000 periods before collecting statistics reveals that the simulations do not converge in a strict sense: waiting one million rather than 500,000 periods does not reduce the standard deviation across simulations of the estimated coefficients (Table 7). It is their average level across simulations, as well as their standard deviations, that are essentially unchanged. But the dispersion of coefficients across simulations does not go to zero when one waits longer. Hence, the economy's response to monetary shocks in the long run exhibits path dependence; it is neither entirely arbitrary, since the means and standard deviations are robust to changes in the waiting period, nor entirely pinned down. The simulations do not become more similar as one waits longer. In other words, in the space of the parameters that summarize its time series properties, the economy settles in a well-defined zone, where prices are 
typically rigid, and that zone shifts in a predictable and understandable way when parameters such as $\gamma$ and $\rho$ change. But where the economy actually lies in that zone is unstable and path-dependent.

\section{Conclusion}

This paper has provided evolutionary foundations for aggregate price level stickiness in the face of shocks to nominal aggregate demand. Stickiness evolves when local interactions are strong and the variance of monetary innovations is low, as an outcome of individual agents' tendency to experiment with alternative pricing rules. A natural extension of the model would be to introduce idiosyncratic shocks, say shocks to production costs. The model would then have the potential to capture the evolution of the cross-sectional distribution of prices. 18 As we already pointed out, the model could be applied to a variety of settings where agents are imperfectly rational, local interactions prevail, and there are aggregate shocks.

\section{APPENDIX}

\section{PROOF OF PROPOSITION 1:}

It is straightforward to check that the proposed equilibrium satisfies the optimality conditions. To prove uniqueness, we take the following steps. First, note that for a given, arbitrary, out-of-equilibrium value of the aggregate price level $p>0$, there exists a solution $\left\{y_{i}, p_{i}\right\}$ to the set of equations (4)-(1) which is symmetrical, i.e., satisfies $y_{i}=y \forall i$, and $p_{i} / p=$ $q \forall i$. Such a solution is given by

$$
\begin{gathered}
y=\left[\frac{M}{P}\left(\frac{\eta}{\eta-1} a \beta \omega\right)^{-\eta}\right]^{1 / 1+\eta(\beta \gamma-1)} \\
q=\left(\frac{\eta}{\eta-1} a \beta \omega\right)^{1 / 1+\eta(\beta \gamma-1)} \\
\times\left(\frac{M}{P}\right)^{\beta \gamma-1 / 1+\eta(\beta \gamma-1)}
\end{gathered}
$$

\footnotetext{
${ }^{18}$ See Saul Lach and Daniel Tsiddon (1992) for an empirical analysis.
}

These formulas define a symmetrical "pseudoequilibrium" such that a firm's optimality conditions are satisfied for a price level which is in general not consistent with the prices set by firms.

Second, note that any equilibrium vector pair $(\mathbf{y}, \mathbf{p})=\left(\left(y_{1}, \ldots, y_{N}\right)^{\prime},\left(p_{1}, \ldots, p_{N}\right)^{\prime}\right)$ must be a fixed point of the mapping $T(p)$ defined by

$$
\begin{aligned}
T(p)(\mathbf{y}, \mathbf{p}) & =(\tilde{\mathbf{y}}, \tilde{\mathbf{p}}) \\
& =\left(\left(\tilde{y}_{1}, \ldots, \tilde{y}_{N}\right)^{\prime},\left(\tilde{p}_{1}, \ldots, \tilde{p}_{N}\right)^{\prime}\right)
\end{aligned}
$$

such that

$$
\begin{gathered}
\tilde{y}_{i}=\frac{M}{p}\left(\frac{\tilde{p}_{i}}{p}\right)^{-\eta} \\
\tilde{p}_{i}=\frac{\eta}{\eta-1} \frac{\tilde{y}_{i}^{\beta-1}}{y_{i-1}^{\beta(1-\gamma)}} a \beta \omega p .
\end{gathered}
$$

That mapping is conditional on any given arbitrary price level $p$. Any equilibrium must be a fixed point of the $T(p)$ transformation associated with its corresponding true equilibrium price level.

Substituting, and eliminating the $\tilde{y}$ s, one can readily see that the $T(p)$ mapping transforms a given vector of prices $\mathbf{p}$ into $\tilde{\mathbf{p}}$ such that

$$
\ln \tilde{p}_{i}=k+\frac{\eta \beta(1-\gamma)}{1+\eta(\beta-1)} \ln p_{i-1}
$$

where $k$ is a constant.

Clearly, if $\gamma>(\eta-1 / \eta)$, then $[\eta \beta(1-$ $\gamma) / 1+\eta(\beta-1)]<1$ and $T(p)$ is a contraction. Its fixed point is unique and can only be the symmetrical pseudo-equilibrium defined by (6) and (7). But given that any equilibrium must be such a fixed point, it follows that any equilibrium is symmetrical. But only one pseudoequilibrium is also an equilibrium, since in equilibrium one must have $q=N^{1 /(\eta-1)}$, which uniquely defines $p$ and $y$ in (6) and (7).

\section{REFERENCES}

Akerlof, George A. and Yellen, Janet L. "A NearRational Model of the Business Cycle, with 
Wage and Price Inertia." Quarterly Journal of Economics, 1985, 100(5), pp. 823-38.

Anderson, Philip W.; Arrow, Kenneth J. and Pines, David, eds. The economy as an evolving complex system: The proceedings of the evolutionary paths of the global economy workshop. Held September, 1987, in Santa Fe, New Mexico. Santa Fe Institute Studies in the Sciences of Complexity, Vol. 5. Redwood City: Addison Wesley, 1988.

Arifovic, Jasmina. "The Behavior of the Exchange Rate in the Genetic Algorithm and Experimental Economies." Journal of Political Economy, 1996, 104(3), pp. 510-41.

Arifovic, Jasmina. "Evolutionary Algorithms in Macroeconomic Models." Macroeconomic Dynamics, 2001, 4(2), pp. 373-414.

Arthur, W. Brian; Durlauf, Steven N. and Lane, David. The economy as an evolving complex system II. Reading: Addison Wesley, 1997.

Ball, Laurence. "Near-Rationality and Inflation in Two Monetary Regimes." National Bureau of Economic Research, Inc., NBER Working Papers: No. 7988, 2000.

Ball, Laurence and Romer, David. "Sticky Prices as Coordination Failure." American Economic Review, 1991, 81(3), pp. 539-52.

Barro, Robert J. and Grossman, Herschel I. "A General Disequilibrium Model of Income and Employment." American Economic Review, 1971, 61(1), pp. 82-93.

Bénassy, Jean-Pascal. "Neo-Keynesian Disequilibrium Theory in a Monetary Economy." Review of Economic Studies, 1975, 42(4), pp. 503-23.

Bénassy, Jean-Pascal. "The Disequilibrium Approach to Monopolistic Price Setting and General Monopolistic Equilibrium." Review of Economic Studies, 1976, 43(1), pp. $69-81$.

Blanchard, Olivier J. "The Wage Price Spiral." Quarterly Journal of Economics, 1986, 101(3), pp. 543-65.

Blanchard, Olivier J. and Kiyotaki, Nobuhiro. "Monopolistic Competition and the Effects of Aggregate Demand." American Economic Review, 1987, 77(4), pp. 647-66.

Bray, Margaret. "Learning, Estimation, and the Stability of Rational Expectations." Journal of Economic Theory, 1982, 26(2), pp. 31839.
Brock, William A. and Durlauf, Steven N. "Discrete Choice with Social Interactions." Review of Economic Studies, 2001, 68(2), pp. 235-60.

Caballero, Ricardo J. and Engel, Eduardo. "Heterogeneity and Output Fluctuations in a Dynamic Menu-Cost Economy." Review of Economic Studies, 1993, 60(1), pp. 95-119.

Caplin, Andrew S. and Spulber, Daniel F. "Menu Costs and the Neutrality of Money." Quarterly Journal of Economics, 1987, 102(4), pp. 703-25.

Durlauf, Steven N. "Multiple Equilibria and Persistence in Aggregate Fluctuations." American Economic Review, 1991, 81(2), pp. $70-74$.

Durlauf, Steven N. "Statistical Mechanics Approaches to Socioeconomic Behavior." National Bureau of Economic Research, Inc., NBER Technical Working Paper: No. 203, 1996.

Ellison, Glenn. "Learning, Local Interaction, and Coordination." Econometrica, 1993, 61(5), pp. 1047-71.

Ellison, Glenn and Fudenberg, Drew. "Rules of Thumb for Social Learning." Journal of Political Economy, 1993, 101(4), pp. 612-43.

Evans, George W. and Honkapohja, Seppo. "Local Convergence of Recursive Learning to Steady States and Cycles in Stochastic Nonlinear Models." Econometrica, 1995, 63(1), pp. 195-206.

Fischer, Stanley. "Long-Term Contracts, Rational Expectations, and the Optimal Money Supply Rule." Journal of Political Economy, 1977, 85(1), pp. 191-205.

Grandmont, Jean-Michel and Laroque, Guy. "Stability, Expectations, and Predetermined Variables," in P. Champsaur and et al., Essays in honor of Edmond Malinvaud, Vol. 1 Microeconomics. Cambridge, MA: MIT Press, 1990, pp. 71-92.

Harrington, Joseph E., Jr. "The Social Selection of Flexible and Rigid Agents." American Economic Review, 1998, 88(1), pp. 63-82.

Harrington, Joseph E., Jr. "Rigidity of Social Systems." Journal of Political Economy, 1999, 107(1), pp. 40-64.

Kiyotaki, Nobuhiro and Wright, Randall. "On Money as a Medium of Exchange." Journal of Political Economy, 1989, 97(4), pp. 927-54. 
Lach, Saul and Tsiddon, Daniel. "The Behavior of Prices and Inflation: An Empirical Analysis of Disaggregated Price Data." Journal of Political Economy, 1992, 100(2), pp. 34989.

LeBaron, Blake; Arthur, W. Brian and Palmer, Richard. "Time Series Properties of an Artificial Stock Market." Journal of Economic Dynamics and Control, 1999, 23(9-10), pp. 1487-1516.

Lindbeck, Assar and Snower, Dennis J. "Price Dynamics and Production Lags." American Economic Review, 1999, 89(2), pp. 81-88.

Lucas, Robert E., Jr. "Expectations and the Neutrality of Money." Journal of Economic Theory, 1972, 4(2), pp. 103-24.

Mankiw, N. Gregory. "Small Menu Costs and Large Business Cycles: A Macroeconomic Model." Quarterly Journal of Economics, 1985, 100(2), pp. 529-38.

Mankiw, N. Gregory and Reis, Ricardo. "Sticky Information versus Sticky Prices: A Proposal to Replace the New Keynesian Phillips Curve." Quarterly Journal of Economics, 2002, 117(4), pp. 1295-1328.

Marcet, Albert and Sargent, Thomas J. "Convergence of Least-Squares Learning in Environments with Hidden State Variables and Private Information." Journal of Political Economy, 1989, 97(6), pp. 1306-22.

Marcet, Albert and Nicolini, Juan Pablo. "Recurrent Hyperinflations and Learning." American Economic Review, 2003, 93(5), pp. 1476-98.

Marimon, Ramon; McGrattan, Ellen and Sar- gent, Thomas J. "Money as a Medium of Exchange in an Economy with Artificially Intelligent Agents." Journal of Economic Dynamics and Control, 1990, 14(2), pp. 32973.

Nelson, Richard and Winter, Sidney. An evolutionary theory of economic change. Cambridge, MA: Harvard University Press, 1985.

Romer, David. Advanced macroeconomics, $2^{\text {nd }}$ Ed. New York: McGraw Hill, 2001.

Rotemberg, Julio J. "Sticky Prices in the United States." Journal of Political Economy, 1982, 90(6), pp. 1187-1211.

Sargent, Thomas J. Bounded rationality in macroeconomics. Arne Ryde Memorial Lectures. Oxford: Oxford University Press, 1993.

Sargent, Thomas J. and Wallace, Neil. "Rational Expectations and the Dynamics of Hyperinflation." International Economic Review, 1973, 14(2), pp. 328-50.

Taylor, John B. "Aggregate Dynamics and Staggered Contracts." Journal of Political Economy, 1980, 88(1), pp. 1-23.

Woodford, Michael. "Imperfect Common Knowledge and the Effects of Monetary Policy," in Philippe Aghion, Roman Frydman, Joseph Stiglitz and Michael Woodford, eds., Knowledge, information, and expectations in modern macroeconomics: In honor of Edmund S. Phelps. Princeton: Princeton University Press, 2002.

Woodford, Michael. Interest and prices: Foundations of a theory of monetary policy. Princeton: Princeton University Press, 2003. 